\title{
ASPECTOS ESTRUTURAIS DA REGIÃO DE SÃO FRANCISCO DE ASSIS, RS •
}

Carlos Leite Maciel Filho e Pedro Luiz Pretz Sartori

Departamento de Geociēncias. Centro de Ciēncias Naturais e Exátas. UFSM. Santa Maria, RS.

\section{RESUMO}

Este trabalho focaliza os aspectos estruturais da região de São Francisco de Assis, no Estado do kio Grande do Sul. A presen ça do "Domo de Itu" (6) não foi confirmada, tendo sido determinada uma anticlinal principal, associada a uma sinclinal e outra anticl $\underline{i}$ nal paralelas, com inclinaçöes muito suaves, mergulhantes para noro este.

As feições estruturais formaram-se não sō pelo mergulho das camadas, mas também por blocos de falhas. Soleiras e diques de dia bāsio intrudiram-se junto às principais linhas de fraqueza.

A idade das estruturas é do Cretáceo e elas estão relacio nadas com 0 arqueamento do Escudo Sul,-rio-grandense.

SUMMARY

MACIEL FILHO,C.L. and SARTORI,P.L.P., 1979. Structural features of the São Francisco de Assis region, RS, Brazil. Ciência e Natura (1): 53-65.

This work focuses on the structural features of the São Francisco de Assis region, in the western part of Rio Grande do sul State, Brazil. An outstanding anticline was determined, having in the southwest a parallel synclineand an other anticline, both of them with low inclination and plunging to the northwest.

The structural ondulations are formed not only by inclina tion beds, but by fault blocks. Diabase sills and dikes were farmed near the principal lines of weakness.

The structures are of the Cretaceous age and are associated with the Sul-rio-grandense Arch, formed during the Wealdenian reacti vation.

INTRODUÇAO

Dentre os aspectos geológicos apresentados pelos municípios de São Francisco de Assis e Santiago, no Rio Grande do Sul, alguns chamam a atenção como è o caso do limite ocidental das ocorréncias

* Trabatho apresentado no 290 Congresso Brasileiro de Geologia, em Belo Horizonte, MG. 
de vitrōfiros e granōfiros da Formação Serra Geral (23) que coinci de com esta região, e o contorno do Planalto Meridional que aí toma direção geral norte-noroeste.

Do ponto de vista estrutural, o primeiro estudo realizado nesta ārea deve-se a CARRARO, EICK \& GAMERMANN (6) que mapearam uma estrutura dômica, na porção norte de São Francisco de Assis e vizi nhanças, denominando-a "Domo de Itu". Nesta interpretação, os auto res salientam a drenagem que teria um padrão anelar radial, devido à provāvel existência de um lacōlito, relacionado com o magmatismo Me sozóico da Bacia do Paranā. O trabalho, contudo, não apresenta dados relativos a medidas de campo que pudessem confirmar o tipo de estru tura citada.

Com o objetivo de se verificar os aspectos estruturaispre sentes na região, provavelmente conectados com os fatos expostos, foi desenvolvido este trabalho que constou da descrição de feições geo morfológicas, medida de altitudes de horizontes guias e localização de falhas, com o auxîlio de fotografias aéreas e dados de campo.

\section{GEOLOGIA DA AREA}

0 mapa que ilustra a geologia da ārea (Figura 1) foi compi lado a partir de MACIEL FILHO; MENEGOTTO \& SARTORI (13), CARRARO, EICK \& GAMERMANN (6) e SCHOBBEENHAUS FILHO (26), e apresentado na escala $1: 500.000$.

Estratigraficamente, trēs são as principais unidades que foram descritas e aparecem no referido mapa:

A sudeste de São Francisco de Assis aparecem arenitos e lü titos de origem fluvial que foram incluídos no Sub-Grupo Rio do Rasto, descrito por WHITE (28), a exemplo do que foi feito pela equipe do Depar tamento Nacional da Produção Mineral na carta ao milionésimo, Folha de Porto Alegre (25). Esta faixa sedimentar, no Estado do Rio Grande do Sul, ē objeto de muitas discussões estratigráficas como se deduz dos trabalhos de MORAES REgO (20), GORDON JUNIOR (11), BEURLEN, SENA SOBRINHO \& MARTINS (4), DELANEY \& GOÑI (9), GAMERMANN (10), BORTOLUZZ Zi (3), CONSTANZO JUNIOR, VIRGili \& MACIEL Filho (8).

Sobrepostos a essas litologias e sem evidencia de discor dāncia regional encontram-se os arenitos componentes da Formação Botuca tu, descrita por GONZAGA DE CAMPOS (5). Esta unidade é bastante es pessa na ārea e apresenta larga distribuição, sendo responsāvel pe los campos arenosos ora descobertos de vegetação e semelhantes a pe quenos "desertos".

Acima dessas camadas sedimentares, encontra-se a Formação Serra Geral, descrita primeiramente por WHITE (28)e constituida por 

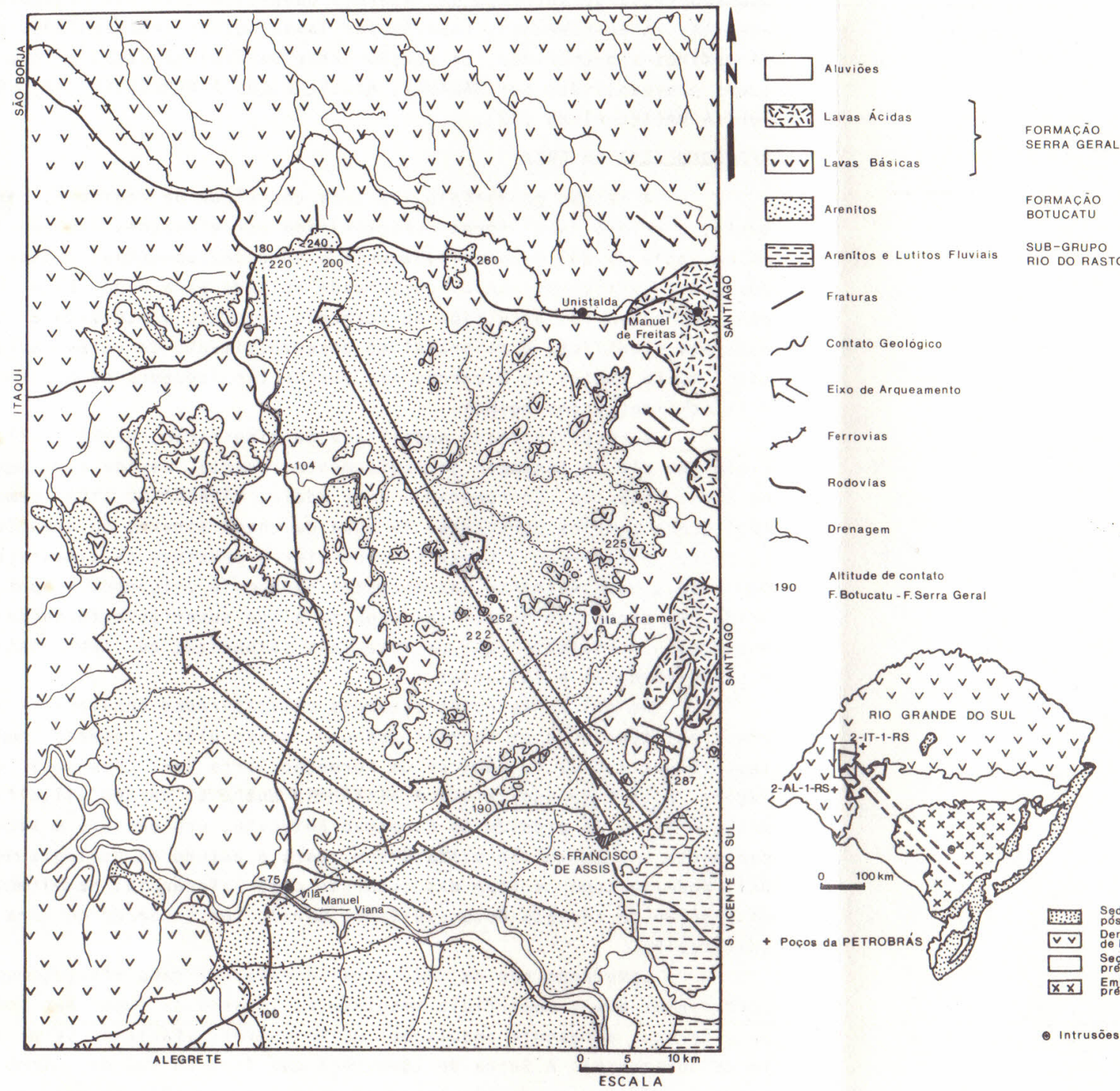

FORMACÁO
AREnitos
BOTUCATU

E=-A Arenitos e Lutitos Fluviais SUB-GRUPO

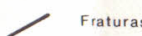

$\sim$ Contato Geológico

E Eixo de Arqueamento

Ferrovias

$\underbrace{}_{\text {Rodovias }}$

b. Drenagem

Altitude de contato

190 F. Botucatu-F.Serra Geral

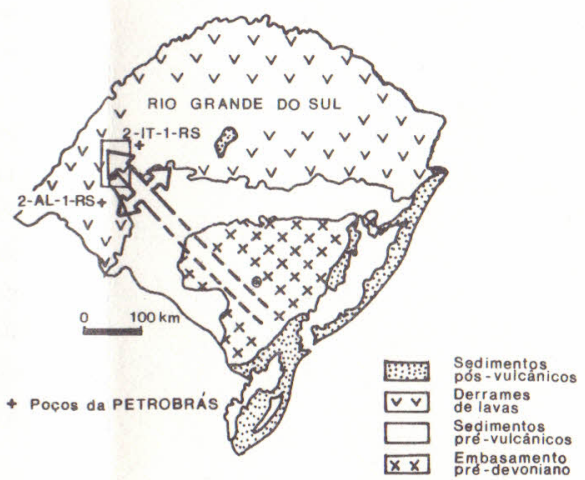

- Intrusōes alcalinas

FIGURA 1. MAPA GEOLOGICO DA REGIAO DE SAO FRANCISCO DE ASSIS, COMPILADO DE (6), (13) e (26), ONDE ESTAO ASSINALADAS AS DUAS ANTICLINAIS MERGULHANTES. NO MAPA INDICE, AO LADO, ESTA TRAÇADO O EIXO DE ARQUEAMENTO DO ESCUDO SUL-RIO-GRANDENSE. 
uma sequência de derrames de natureza basāltica com intercalaçõse de arenitos intertrapeanos, coberta por lavas ácidas representadas por vitrōfiros e granōfiros, na porção leste da ārea mapeada, conforme es tudos desenvolvidos por SARTORI, MACIEL FILHO \& MENEGOTTO (24) e SAR TORI \& MACIEL FILHO (23).

\section{GEOMORFOLOGIA DA AREA}

A feição geomorfolōgica mais conspĩcua da região é, certa mente, o relevo tabuliforme caracterizado por elevações com topo pla no na cota de $200 \mathrm{~m}$ aproximadamente e encostas abruptas, muitas ve zes quase verticais, com a concavidade voltada para cima. Esta fei ção de relevo foi esculpida na Formação Botucatu que,devido a sua natureza arenîtica, é favorāvel ao desenvolvimento de relêvo aciden tado, muito embora as escarpas não seriam tão ingremes se não fosse a silicificação das mesmas.

A respeito desta modalidade de cimentação, WERNICK (27)con cluiu ser ela um fenōmeno geologicamente recente, devido a variações no nível freātico. Corroborando esta idēia, PARAGUASSU (16) demons trou que a simples percolação da àgua da chuva atravēs do arenito e posterior evaporação é capaz de propiciar o processo de cimentação. Com isso, possivelmente, as encostas tenham se originado e após so frido uma deposição de sỉlica, próxima a sua superfície,tornando-se muito mais resistentes que os materiais sotopostos ou sobrepostos, ficando abruptas e salientes.

Ao galgar-se estas escarpas silicificadas constata-se sem pre a existência de um terreno arenoso, quase plano, capeado frequen temente por rochas vulcānicas da Formação Serra Geral nas suas ele vações. Este fato indica que a distāncia entre as partes silicifica das e o topo, jā erodido da Formação Botucatu, era pequena e aprox $\underline{j}$ madamente constante. Em vista disso, para o estudo da geologia regio nal, pode-se tomar o topo das escarpas como referéncia, na delineação da posição do contato Botucatu-Serra Geral, sem incorrer em erro s $\underline{j}$ gnificativo.

Lembrando que de modo geral o relevo è tabuliforme,deve-se acrescentar que a superfície imagināria, ligando os topos de todas as escarpas, apresenta ondulações muito suaves, afastando-se portan to da horizontal. A Serra do Iguariaçá que fica ao sul da estrada São Borja-Santiago e na porção leste do mapa é bordejada por uma série de cerros que mostram leve inclinação dos seus topos para nordeste. A prōpria Serra constituiria,em parte, uma cuesta. Aliās, o mapa geomorfológico elaborado pelo Instituto Nacional de Colonização e Reforma Agräria considera cuestas, muitas dessas escarpas. Na Foto 1 
são vistos dois cerros, com inclinações divergentes em seus topos, dan do a idéia de uma antiforma.

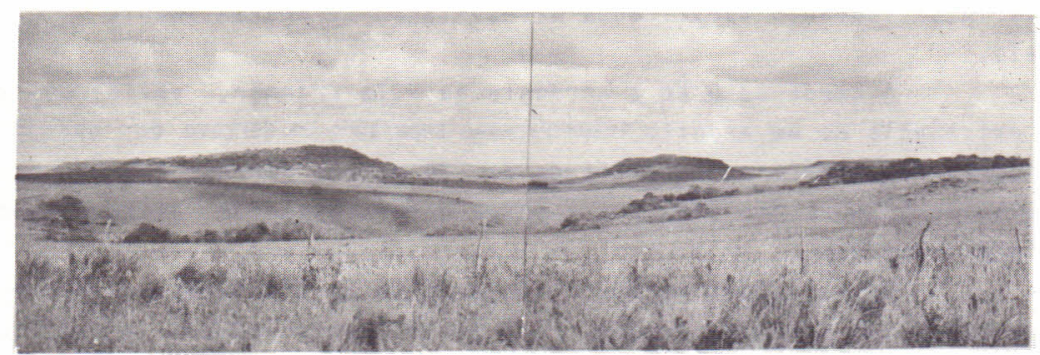

Foto 1. Cerros mantidos pelo arenito silicificado, situados a oes te da Vila Kraemer, mostrando a disposição do topo da For mação Botucatu em antiforma.

A encosta do Planalto, na parte leste do mapa, possui um relevo mais acidentado, fugindo ao padrão das chapadas, com grandes alinhamentos devidos à falhamentos. Esta ārea recai sobre o domỉnio dos basaltos.

As maiores altitudes estão na faixa dos $400 \mathrm{~m}$, situadas tam bēm na porção leste do mapa e, compõem a superfīcie do planalto, mo dulada por coxilhas de pequena altura. Nesta superfície afloram as rochas vulcânicas àcidas.

No extremo oposto, encontram-se as coxilhas da planície pam peana, na altitude aproximada dos $100 \mathrm{~m}$, sobre basaltos e arenitos. POSIÇAOO DOS HORIZONTES GUIAS

Durante o reconhecimento de campo buscou-se elementos pa ra se traçar as estruturas de dimensões regionais. Com exceção de um caso, as medidas locais de direção e mergulho das camadas não têm va lor para a interpretação das estruturas, pois assim como a estratị ficação cruzada dos arenitos da Formação Botucatu não serve para obje tivos ligados à geologia estrutural, especialmente onde as inclina ções são suaves, tambēm as locais do contato Botucatu-Serra Geral não tēm significação tectōnica e podem representar acidentes da paleoto pografia prē-derrame.

Aceita-se, entretanto, que o contato entre derrames, mesmo quando existe uma delgada camada de arenito entre eles, revele at tudes de significado para o estudo em questão. Este fato estā liga da à crença de que as lavas de um vulcanismo fissural tenham assum do uma superfície horizontal ou quase horizontal, logo após a extru são. Raramente, no entanto, houve a oportunidade de se executartais 
medidas, pois muitas vezes a exposição era precāria ou mostrava irre gularidades próprias da superfície da lava. A maior parte dos areni tos intertrapeanos verificados apresentavam-se aparentemente horizon tais.

A cerca de $6 \mathrm{Km}$ a nordeste da Vila Kraemer, verificou-se a existência de um arenito intertrapeano separando um derrame de basalto e outro de vitrōfiro, na altitude de $320 \mathrm{~m}$, com direção $\mathrm{N} 50^{\circ} \mathrm{W}$ e mer gulho de $8^{\circ}$ para NE. Esta foi a ūnica determinação de atitude com algum interesse.

As restantes medidas limitaram-se às altitudes dos horizon tes guias, em diversos locais. Para tanto, contou-se com o auxilio de altimetro tipo Paulin e de cartas topogrāficas, na escala 1:50.000, elaboradas pela D.S.G. do Ministērio da Guerra.

Prosseguindo, a nordeste da Vila Kraemer encontra-se, $3 \mathrm{Km}$ ao norte do afloramento descrito, outro arenito intertrapeanoa $271 \mathrm{~m}$ de altitude; $3 \mathrm{~km}$ mais alēm, na mesma direção, acha-se o contato Bo tucatu-Serra Geral na cota de $225 \mathrm{~m}$.

0 mesmo contato Botucatu-Serra Geral teve suas maiores al titudes medidas segundo um alinhamento noroeste. Fora da ārea abran gida pelo mapa e a sudeste de São Francisco de Assis, o morro teste munho de Loreto, com seu ponto culminante a $366 \mathrm{~m}$ de altitude, apre senta uma escarpa de arenito silicificado prōxima ao topo. Na ārea mapeada a maior altitude para o topo da Formação Botucatu,a $287 \mathrm{~m}$, foi detectada na estrada São Francisco de Assis - Santiago, a $13 \mathrm{Km}$ daquela cidade. Prōximo à Vila Kraemer esse contato estā encoberto, encontrando-se, no entanto, mostras de basalto a $288 \mathrm{~m}$ que certamente não estão longe daquele horizonte guia, o qual deve estar em torno dos $280 \mathrm{~m}$ de altitude. A oeste desta Vila a estrada segue com pouca variação de altitude encontrando-se ocorrências de solos derivados de basalto e de arenito, devendo portanto a superfície de referéncia manter aquela altitude. A $10 \mathrm{Km}$ da Vila Kraemer constatou-se Areni to Botucatu na cota de $252 \mathrm{~m}$. As ocorrências mais setentrionais des te arenito, na ārea mapeada, chegam até $240 \mathrm{~m}$ de altitude.

Pouco fora do alinhamento mencionado ocorre uma mancha de arenito a W-NW de Unistalda que parece, devido a espessura, corres ponder ā Formação Botucatu. O contato com o basalto que lhe estā aci ma atinge a cota de $260 \mathrm{~m}$. e por isso hä dūvidas sobre a posição es tratigräfica deste arenito.

Por outro lado, na porção central do mapa e numa direção noroeste existe uma sērie de ocorrēncias esparsas de basalto em al titudes menores com relação às anteriormente citadas. Assim, na es trada São Francisco de Assis - Manuel Viana aparece basalto na cota 
de $190 \mathrm{~m}$. e a noroeste deste ponto, numa mancha maior de basalto, en contra-se o segundo derrame a $236 \mathrm{~m}$ de altitude. Ao longo da estra da Manuel Viana - São Borja e a $3 \mathrm{Km}$ ao sul do Rio Itu, encontra-se - arenito intertrapeano entre o primeiro e segundo derrames numa alti tude de $150 \mathrm{~m}$; naquele rio, o primeiro derrame jaz a. $104 \mathrm{~m}$. A $3 \mathrm{~km}$ e a $5 \mathrm{~km}$ ao norte do mesmo rio, o contato Botucatu - Serra Geral ele va-se a $125 \mathrm{~m}$., respectivamente.

Aproximadamente a $25 \mathrm{Km}$ do passo sobre o Rio Itu,encontrą - se o entroncamento com a estrada São Borja-Santiago e a $300 \mathrm{~m}$ des te ponto, na altitude de $180 \mathrm{~m}$., situa-se o primeiro derrame de ba salto, devendo o contato com a Formação Botucatu estar um pouco abai xo. A partir daī, e pela ūitima estrada, foi realizado um levanta mento no sentido oeste-leste. A $1 \mathrm{Km}$ ocorre o Arenito Botucatu a $220 \mathrm{~m}$, a $2 \mathrm{Km}$ o contato com a formação sobreposta a $240 \mathrm{~m}$ e a $7 \mathrm{Km}$, omesmo contato um pouco acima de $200 \mathrm{~m}$ de altitude. A $10,5 \mathrm{~km}$ daquele en troncamente aparece 0 arenito intertrapeano entre o primeiro e segun do derrames a pouco mais de $200 \mathrm{~m}$.

A sudoeste daquelas ocorrēncias esparsas de basalto, na por ção central do mapa, desenvolve-se uma faixa de Arenito Botucatu que atinge em muitos pontos, conforme as cartas topogrāficas, altitudes maiores que os basaltos que estão a nordeste e sudeste.

Para facilitar a visualização dos fatos expostos, foi tra çada a secção geolōgica A-A' (Figura 2). Esta,inicia na Vila de Ma nuel Viana, onde a base da Formação Serra Geral estā abaixo do nĩvel do Rio Ibicui que banha o derrame inferior a $75 \mathrm{~m}$. de altitude. A nordeste desta vila, a linha de contato passaria acima dos cerros mantidos pelo Arenito Botucatu que atingem mais de $200 \mathrm{~m}$ de altitude. Mais a nordeste, tal linha passa a 190m (ponto jā mencionado) para logo adiante alcançar altitudes maiores, conforme se constatouna car ta topogrāfica. Por fim, o contato Botucatu-Serra Geral desce e fí ca encoberto pela espessa seqüência de derrames basāiticos e grano fíricos.

Ao sul de Manuel Viana esse nīvel de referēncia mantēm-se em torno da cota de $100 \mathrm{~m}$. No poço 2-AL-1-RS da Petrobrās, situado em Alegrete e distante aproximadamente $35 \mathrm{~km}$ do ūitimo afloramento - contato (Figura 1), encontra-se à altitude de $52 \mathrm{~m}$ (15). Isto in dica que a S-SW da referida vila, as camadas mantēm uma atitude prá ticamente horizontal.

No outro extremo, o poço 2-IT-1-RS, situado a uns $15 \mathrm{~km} \mathrm{a}$ leste de Unistalda, mostra o mesmo contato a $-70 \mathrm{~m}(15)$ e (19).

FRATURAS E INTRUSOES

Durante o mapeamento do Municīpio de São Francisco de Assis 


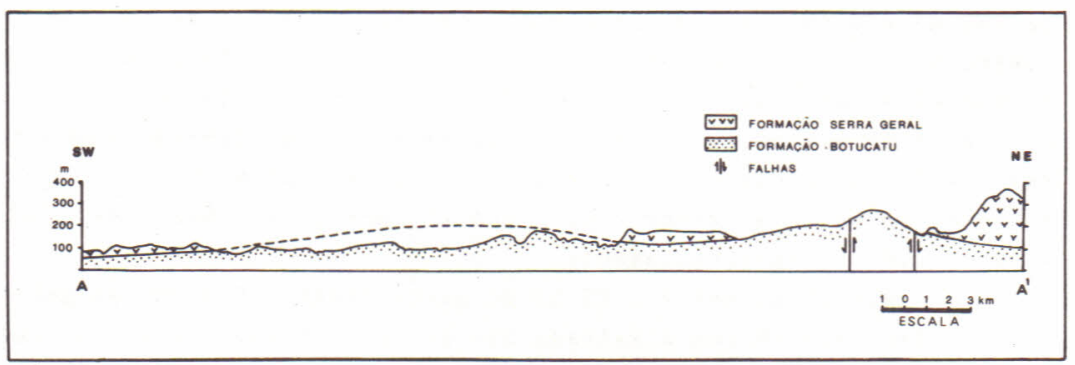

Figura 2. Secção geológica $A-A^{\prime}$, entre Manuel Viana (SW) e a en costa do planalto (NE) ao norte da cidade de São Fran cisco de Assis, mostrando as duas antiformas, eviden ciadas pelo contato Botucatu-Serra Geral, e o horst.

(13) e posteriormente à realização deste trabalho, foram assinalados alinhamentos, vales e escarpas, em fotografias aéreas que sugeriam fraturamentos; a direção predominante dessas feições é noroestee são mais conspicuas na faixa correspondente à encosta do planalto.

Em alguns lugares hā indicações de falhas.Aproximadamente $15 \mathrm{Km}$ a leste da cidade de São Francisco de Assis observou-se que a chapada mantida pelo Arenito Botucatu forma um degrau, de direçãono roeste, mostrando que o bloco de nordeste subiu em relação ao de su doeste. Ao norte da mesma cidade, a cerca de $10 \mathrm{~km}$, verificou-sequa tro situações em que a mesma superfīcie da chapada mostra merguthos cada vez mais acentuados nas proximidades de alinhamentos estruturais, feição esta indicativa de dobras de arrasto. Estas falhas formam um horst com duas falhas escalonadas de cada lado (Figura 2 ).

Em poucos locais houve a oportunidade de se constatar, no campo, indīcios de falhas. Um deles situa-se na porção oeste do ma pa (Figura 1) e corresponde à zona de falha que separa os afloramen tos da Formação Botucatu a nordeste dos da Formação Serra Geral a su deste, encontrados em cotas mais baixas que os daquela. Nesta zona a rocha está intensamente fraturada e constitui um cataclasito.A di reção de diaclasamento principal é $\mathrm{N} 60^{\circ}-70^{\circ} \mathrm{W}$. A nordeste dessa fa lha está assinalada, no mapa, outra fratura que toma realce pelo al $\underline{i}$ nhamento dos afloramentos de arenito, junto ao vale que possivelmen te se tornou mais resistente đevido ao processo de silicificação.Pou co mais ao sul desses afloramentos foi constatado um padrão de dia clasamento com direção geral $\mathrm{N} 60^{\circ} \mathrm{W}$.

Associada a essas fraturas deve-se mencionar a ocorrência de duas intrusões: uma soleira junto à cidade de São Francisco de As 
sis e um dique a sudeste da mesma. A primeira corresponde a um dia básio porfirítico contendo olivina (13). O dique, tem cerca de meio metro de espessura, apresenta-se totalmente alterado, e situa-se no alinhamento de falhas que acompanham a antiforma mais setentrional. INTERPRETAÇAOO DOS DADOS

Compondo o quadro geral das estruturas na ārea, a partir das observações geomorfolōgicas e altimétricas dos horizontes guias, pode-se dizer que as duas formações principais da região mostram sua ves ondulações, especialmente a superfície de contato Botucatu-Serra Geral e configuram, em dimensões regionais, duas antiformas e uma sinforma mergulhantes para noroeste, com eixos principais aproxima damente paralelos. A estrutura mais destacada é a antiforma seten trional (Figura 1).

De acordo com esta interpretação, na porçã̃ norte do Muni cỉpio de São Francisco de Assis e suas vizinhanças, não mais ter-se -ia um domo, o de Itu (6), e sim duas antiformas mergulhantes.

Os falhamentos observados acompanham a tendência dessas ondulações pois alēm de possuirem a mesma direção geral, soergueram os blocos das antiformas.

0 fato de o topo da Formação Botucatu se apresentar ondu lado poderia ser debitado à paleotopografia dos arenitos. No entan to, foi verificado que os arenitos intertrapeanos e os derrames de basalto tambēm estão influenciados pelo mesmo fenômeno. Disso, con clui-se que estas estruturas devem ter origem tectônica, podendo se rem tratadas como dobras sinclinal e anticlinais. Como estão asso ciadas às falhas é possīvel que tenham resultado de estruturasdeblo $\cos$.

A idade desse tectonismo ē certamente pōs-Serra Geral,pois os derrames de lavas tambēm foram afetados pelo fenōmeno.

\section{CONTEXTO TECTÔNICO REGIONAL}

0 prolongamento das duas anticlinais resulta numa junção a sudeste da cidade de São Francisco de Assis, passando então a coin cidir praticamente com eixo de arqueamento do Escudo sul-rio-granden se mencionado em (22) e (1).

Quanto às intrusões devemos referir o seguinte: PICADA (17) estudando a tectōnica do Escudo Sul-rio-grandense cita que o sis tema de falhas noroeste $\bar{e}$, ocasionalmente preenchido por diques de diabásio; prōximo ao eixo de arqueamento do Escudo, RIBEIRO(21) en controu nove chaminés de rochas alcalinas, ao sul do Rio Camaquã e descreveu também a presença de diques de diabásio em fraturas de di 
reção noroeste com uma disposição bem mais ampla, principalmente, en tre Santana da Boa Vista e Caçapava do Sul; mais tarde,PINTO, VILLWOCK \& LOSS (18) verificaram 32 ocorrências dessas chaminés nesta região. A presença de diques de diabásio com direção geral noroeste bem como de chaminés de rochas alcalinas, indicam condições de me nor tensão nesta direção do eixo de arqueamento do Escudo que provo ca tal distribuição de tensões.

Este fenōmeno deve ter ocorrido em diferentes ēpocas pois estā ligado à formação da Bacia do Paranā. No entanto, a manifesta ção que causou as estruturas em questão ē posteior ao vulcanismo de idade Jurássico Superior - Cretāceo Médio (2), (24) que afetou a cị tada bacia.

NORTHFLEET, MEDEIROS \& MUHLMANN (14), assinalaram no mapa paleotectônico da Bacia do Paranā, correspondendo ao fim do Cretáceo Inferior, o referido eixo de arqueamento sobre a região estudada. As sim, levando em conta que um traquito proveniente de uma das chami nés de rochas alcalinas forneceu a idade de 80 milhões de anos e como não se conhecem evidências de atividades similares em ēpoca posterior, podemos admitir idade do Cretāceo para essas estruturas que se formaram em decorrência da reativação Weazdeniana (1).

As ondulações descritas representariam, portanto, a termi nação desse soerguimento no Cretčeo Superior, na região estudada, en volvendo, em parte, flexão e, em parte, jogo de falhas, com aspectos de uma tectōnica germanōtipa, jā que "a estrutura tectônica da Bacia do Paraná é o resultado final de falhamentos verticais, inexistindo dobramentos tangenciais regionais. Há certamente uma relação íntima entre a tectônica e intrusões, pois quase todas falhas profundas en contram-se preenchidas por diabásio, havendo abundantes e extensas soleiras"(12).

\section{CONCLUSOES}

$\mathrm{Na}$ região de Sao Francisco de Assis foram descritos aspec tos estruturais de natureza tectōnica que coincidem com o limite oci dental de ocorrência dos derrames de lavas ācidas da Formação Serra Geral e com o contorno do rebordo do Planalto Meridional, no Rio Grande do Sul.

Esta tectōnica estā manifesta pela presença de uma anti clinal mais expressiva, seguida de sinclinal e anticlinal a sudoeste, todas com inclinações muito suaves, de direção geral NW-SE e mer gulho para noroeste. Estes altos e baixos estruturais são tambēm re sultantes de blocos de falha. Soleiras e diques de diabāsio situam -se junto às principais linhas de fraqueza. 
A existēncia do Domo de Itu (6), por conseqüēncia,não foi confirmada.

0 prolongamento das duas anticlinais no sentido sudeste re sulta numa junção que coincide, praticamente, com o eixo de arquea mento do Escudo Sul-rio-grandense.

Essas estruturas, portanto, estão associadas ao arqueamen to do Escudo e correspondem à terminação noroeste do mesmo. A idade è referida ao Cretāceo e o fato relaciona-se à reativação Wealdeniana.

\section{AGRADECIMENTOS}

Os autores agradecem aos Professores Dr. Yociteru Hasui e Dr. Georg Sadowski, pelas sugestões apresentadas; à Professora Maria da Graça Barros Sartori, pelo desenho das figuras; à Senhora Mārcia Saad, pela organização das referēncias bibliogrāficas.

\section{BIBLIOGRAF I A CITADA}

1. ALMEIDA,F.F.M. Diferenciação tectônica da Plataforma. Brasileira. In: CONGRESSO BRASILEIRO DE GEOLOGIA, 230̣, Salvador,1969. Anais ... Salvador, SBG, 1969, p.31-46.

2. AMARAL, G.;CORDANI, V.G.; KAWASSHITA,K.;REYNOLDS, J.H. "Potassium ar gon ages of basaltic rocks from Southern Brazil".Geoch. Cosmoch. Acta.30 (2): 159-189, 1966.

3. BORTOLUZZI,C.A. Contribuição à geologia da região de Santa Maria, Rio Grande do Sul, Brasil. Pesquisa., Porto Alegre, UfRGS, (4): $7-86,1974$.

4. BEURLEN, K.; SENA SOBRINHO,M.;MARTINS,K. Formações gondwânicas do Rio Grande do Sul. B. Mus. Nac. Ser. Geol. (22): 1-55, 1955.

5. CAMPOS,L.F.G. de Rezatório da Comissão Geográfica e Geológica de São Paulo. São Paulo, 1889, p.21-34.

6. CARRARO,C.C.;EICK,N.C.;GAMERMANN,N. O Domo de Itu. Porto Alegre, Instituto de Geociēncias da UFRGS, 1972. (Mapa,3).

7. CORDANI,U.G.;HALPERN,M.;BERENHOLC,M. Comentārios sobre as deter minações geocronolögicas da folha de Porto Alegre. In:DEPARTA MENTO NACIONAL DA PRODUÇÃO MINERAL. Carta geológica do Brasiz ao milionésimo; folha Porto Alegre SH. 22 e folha Lagoa Mirim SI.22. Brasilia, 1974, p.70-84.

8. COSTANZO JUNIOR,J.; VIRGILI,J.C.;MACIEL FILHO,C.L. "Contribuiçãoà cartografia geotécnica da região de Santa Maria (RS)". In:CON GRESSO BRASILEIRO DE GEOLOGIA DE ENGENHARIA, 20, São Paulo,1978. Anais ... São Paulo, ABGE, 1978, 1: 267-280.

9. DELANEY,P.J.V. \& GONI,J.C. Correlação preliminar entre as forma ções gondwānicas do Uruguai e do Rio Grande do Sul, Brasil.B. 
Par. Geogr., Curitiba, (8/9): 3-21, 1963.

10. GAMERMANn,N. Formação Rosārio do Sut. Pesquisa., UFRgS Porto Ale gre, (2): 5-35, 1973 .

11. GORDON JUNIOR,M. Classification of the Gondwanic rocks of Para ná, Santa Catarina and Rio Grande do Sul. Notas Prelimin.Est., Rio de Janeiro, DGM, (54): 1-7, 1947.

12. LOCZY,L. \& LADEIRA,E.A. Geologia estrutural e introducão à Geo tectônica. São Paulo, Ed. Edgard Blücher - CNPq, 1976,528p.

13. MACIEL FILHO,C.L.;MENEgOTTO,E.;SARTORI,P.L. Geologia do Munici pio de São Francisco de Assis, RS. Santa Maria, Depto Geociēn cias, UFSM, 1971, 29p. (Pubi. esp., 4).

14. NORTHFLEET,A.A.;MEDEIROS,R.A.;MUHLMANN,H. Reavaliação dos dados geolōgicos da Bacia do Paranā. B.Tec.Pètrobrás, Rio de Janeí ro, 12 (3): 291-346, 1969.

15. OLIVEIRA,M.A.M. Possibilidades de geração e migração tardias de petrōleo na Bacia do Paranā. In: CONGRESSO BRASILEIRO DE GEO LOGIA, 250, São Paulo, 1971.Anais ... São Paulo, 1971, SBG, $1971,3: 139-158$.

16. PARAgUASSU,A.B. Experimental silicification of sandstone. Geol. SOC.Am.BuZZ. 83: 2853-2858.

17. PICADA,R.S. Ensaio sobre a tectōnica do Escudo Sul-Riograndense Caracterização dos sistemas de falhas. In: CONGRESSO BRASIIEI RO DE GEOLOGIA, 250, São Paulo, 1971, Anais ... São Paulo,SBG, 1971, 1: 167-191.

18. PINTO,J.F.;VILLWOCK,J.A.;LOSS,E.L. Relatörio da geologia da pro vincia alcalina do Rio Grande do Sul, folhas Arroio Barracão e Arroio da Bica. Porto Alegre, Inst. Geoc. UFRGS,MME, DNPM, MEC, $1975,48 \mathrm{p}$.

19. RAMOS,A.N. \& FORMOSO,M.L.L. Argizominerais das rochas sedimenta res da Bacia do Paraná. Rio de Janeiro, Petrobrās, 1975, 77p. i1. (Petrobrās, serie Ciēncia-Tëcnica-Petrōleo, seção: Explo ração de Petrōleo, 9).

20. REgo,L.F.M. A geologia do Petróleo no Estado de São Paulo. $B$. Ser.Geol.Mine., Rio de Janeiro, (46), 1930.

21. RIBEIRO,M. Uma provĩncia alcalina no Rio Grande do Sul. I.Estudos preliminares. Iheringia. Geologia, Porto Alegre, (1):59-71, 1971 .

22. SANFORD,R.M. \& LANGE,F,W. Basin-study approach to oilevolution of Paranā miogeosyncline, South Brazil. Am.Ass.Petr.Geol. Buzz., Tulsa, 44 (8): 1316.1370 ,

23. SARTORI,P.L. \& MACIEL FILHO,C.L. Petrografia da sequência vulcâ 
nica da Formação Serra Geral no rebordo ocidental do Planal to Meridional, RS. In: CONGRESSO BRASILEIRO DE GEOLOGIA, 299, Belo Horizonte, 1976, Anais... (no prelo).

24. SARTORI,P.L.;MACIEL FILHO,C.L.;MENEGOTTO,E. Contribuição ao es tudo das rochas vulcânicas da Bacia do Paranā na região de Santa Maria. RS.Rev. Bras. Geoc. São Paulo, 5(3): 141-159, 1975.

25. SCHOBBENHAUS FILHO,C., comp. Carta geológica do Brasiz ao mizio nésimo; folha Porto Alegre (SH.22) e folha Lagoa Mirim(SI.22). Brasilia, 1974.

26. SCHOBBENHAUS FILHO,C., comp. Carta geológica do Brasiz ao mizio nésimo; folha Uruguaiana (SH:21). Brasilia, DNPM, 1974.

27. WERNICK,e: A silicificação do Arenito Botucatu na quadrícula de Rio Claro, Estado de São Paulo. Av.Div.Geol.Miner, Rio de Ja neiro, (40), 1965.

28. WHITE, I.C. Relatōrio sobre as "coal measures" e rochas associa das do Sul do Brasil. In: Relatōrio final da Comissão de Es tudos das Minas de Carvão. s.1.p., 1908, parte 1, geologia, p. 1-201.

Recebido em junho, 1979; aceito em agosto, 1979. 
$\because$

$+\infty+\infty+$ 